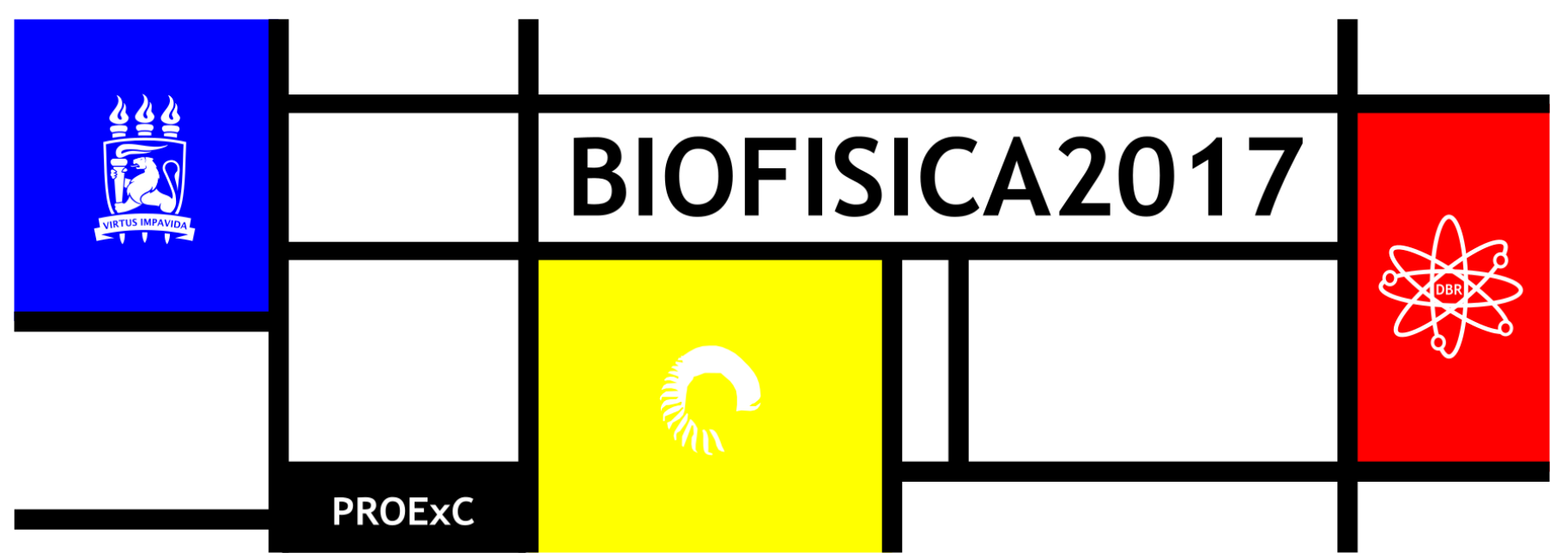

\title{
AVALIAÇÃO IN VITRO DO PROCESSO DE ADESÃO DE MACRÓFAGOS J774 COM ARCABOUÇOS 3D DE BIOPOLÍMERO DE CANA-DE-AÇÚCAR
}

Laryssa Kathleen Mendonça Ferreira1*, Eduardo Muniz-Filho¹, Erwelly Barros de Oliveira², Silvania Tavares Paz ${ }^{3}$, Fábio André Brayner dos Santos ${ }^{4}$, Luiz Carlos Alves ${ }^{4}$, José Lamartine de Andrade Aguiar ${ }^{5}$, Eliete Cavalcanti da Silva ${ }^{1}$, Paloma Lys de Medeiros ${ }^{1,2,3}$

\footnotetext{
${ }^{1}$ Laboratório de Cultura de Tecido - Dept ${ }^{\circ}$. de Histologia e Embriologia (LCT-DHE, CB/UFPE); ${ }^{2}$ Programa de Pós-graduação em Inovação Terapêutica (PPGIT/UFPE), ${ }^{3}$ Programa de Pós-graduação em Patologia (POSPAT-CCS/UFPE), ${ }^{4}$ Setor de Microscopia Eletrônica - Laboratório de Imunopatologia Keizo Azami (LIKA/UFPE); ${ }^{5}$ Programa de Pós-graduação em Cirurgia do Hospital das Clínicas-CCS/UFPE *laryssakathleen@outlook.com
}

\section{INTRODUÇÃO}

A engenharia de tecidos constitui uma área emergente da biotecnologia que se enquadra na pesquisa multidisciplinar e ao associar-se à biologia estrutural e biomimética, engloba conhecimentos da engenharia de materiais e ciências biomédicas, destacando-se devido à abordagem promissora no reparo e regeneração de tecidos eventualmente lesados por traumas físicos ou químicos, doenças e/ou senescência (PERTILE et al., 2007; BOROJEVIK, 2008; PLACE; EVANS; STEVENS, 2009; SÀNDOR, 2013). Logo, a confiabilidade para utilização de um material biológico na engenharia de tecidos dependerá, primeiramente, dentre diversas propriedades avaliadas, de sua biocompatibilidade; ou seja, da avaliação in vitro das fases de adesão e proliferação de determinadas células em contato com o biomaterial (MADLA et al., 2005; PLACE; EVANS; STEVENS, 2009, MAGER et al., 2011).

Neste contexto, os macrófagos desempenham papel crítico no desenvolvimento do processo de cicatrização, modulando a produção de quimiocinas e fatores de crescimento que promovem proliferação celular e síntese protéica. As células J774 constituem uma linhagem de macrófagos diferenciados de pró-monócitos murinos, ou seja, o mesmo tipo celular envolvido na cicatrização (WILSON, 1997). Essas células têm características morfológicas bastante variáveis que dependem de seu estado de atividade funcional e do tecido que habitam (JUNQUEIRA; CARNEIRO, 2013). Desta forma, promover a adesão de células a um biomaterial pode ajudar na integração do tecido conectivo mole com o implante, repercutindo no desenvolvimento de novas ferramentas (CARVALHO et al., 2010; MAGER et al., 2011; PIRES et al., 2015).

Os biopolímeros despontam como biomateriais inovadores, em função da sua biocompatibilidade e o biopolímero de cana-deaçúcar (BCA), um exopolissacarídeo produzido a partir da fermentação do melaço pela bactéria Zoogloea sp., vem sendo utilizado em diversas aplicações nas áreas das Ciências da Saúde e da Biologia (PATERSON-BEEDLE et al., 2000; CASTRO, et al., 2004; AGUIAR et al., 2007; CAVALCANTE, et al., 2007; SILVEIRA et al.,
2007; MAYER et al., 2011; MARTINS et al., 2013; SILVEIRA et al., 2014; ABREU et al., 2016). Em função do exposto, objetivamos avaliar in vitro o processo de adesão de macrófagos $\mathrm{J774}$ com arcabouços 3D a base de biopolímero de cana-de-açúcar.

\section{MATERIAIS E MÉTODOS}

As esponjas de biopolímero de cana-de-açúcar foram gentilmente doadas pelo Coordenador grupo de pesquisa com Biopolímeros de cana-de-açúcar, Prof. Dr. José Lamartine de Andrade Aguiar, ligado ao Programa de Pós-graduação em Cirurgia do Hospital das Clínicas (CCS-UFPE).

A referida pesquisa foi realizada no Laboratório de Cultura de Tecidos do Departamento de Histologia e Embriologia (LCT-DHE) do Centro de Biociências da UFPE. Os macrófagos foram descongelados em banho-maria e posteriormente, centrifugados sob refrigeração. 0 pellet celular formado foi ressuspendido em meio DMEM suplementado com $10 \%$ de soro fetal bovino e mistura de antibióticos. As células foram cultivadas e mantidas em estufa com $5 \%$ de $\mathrm{CO}_{2}$, a $37^{\circ} \mathrm{C}$ e umidade controlada. Os macrófagos $\left(10^{5}\right.$ células $/ \mathrm{mL}$ ) foram colocados em placas de cultura de 06 poços em contato com as esponjas de BCA e acompanhados por um período de 24,48 e 72 horas. A morfologia das células cultivados nas esponjas foi analisada através de sistema de vídeo microscopia e parte desse material foi processado para a análise histológica. A biocompatibilidade dessas células com os arcabouços 3D foi acompanhada através de microscópio invertido de contraste de fase (LEICA) com sistema de captura de imagem e uma avaliação mais refinada foi realizada com auxílio da microscopia eletrônica de varredura (MEV). Para o processamento histotécnico, procedeuse a fixação das esponjas em paraformaldeído 4\% (tamponado) com posterior inclusão em parafina. Após a confecção dos blocos, cortes histológicos $(5 \mu \mathrm{m})$ foram realizados em micrótomo e as preparações foram coradas com corante azul de toluidina. As preparações com o biomaterial foram observadas com uso de Microscópio Motic (BA 200) acoplado com câmera (MOTICAM 1000) 
para registro das fotomicrografias. Como parte de uma colaboração com pesquisadores do Setor de Microscopia Eletrônica do Laboratório de Imunopatologia Keizo Azami (LIKA/UFPE), pequenas amostras das esponjas com as células foram fixadas em solução de $0,5 \mathrm{~mL}$ de glutaraldeído e $4,5 \mathrm{~mL}$ de solução tampão $(\mathrm{pH}=7,4)$, e em seguida, preparadas de acordo com protocolo de processamento para a microscopia eletrônica de varredura (MEV).

\section{RESULTADOS E DISCUSSÃO}

Os macrófagos cultivados em garrafas de cultura para expansão das células apresentaram-se com aspecto fibroblastóide característico da linhagem estudada (Figura 1).
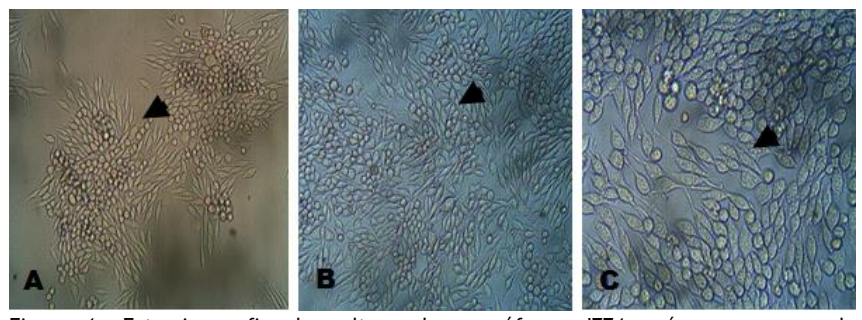

Figura 1. Fotomicrografia da cultura de macrófagos $\mathbf{J 7 7 4}$ após o processo de descongelamento, realizada com microscópio invertido com contraste de fase. A) Início do surgimento das colônias de macrófagos (cabeça de seta) com 24 horas de cultivo. B) Nota-se formação de monocamada com 48 horas (cabeça de seta). C) Ampliação de uma região da figura $B$, destacando células com aspecto fibroblastóide (cabeça de seta). A e B: aumento de 100X; C: aumento de 200X

Ao avaliarmos a morfologia dos macrófagos $\mathrm{J774}$ cultivados em arcabouços 3D de BCA, com auxílio da microscopia comum, observamos que as esponjas suportaram satisfatoriamente $\mathrm{O}$ crescimento dessas células com 24 horas; ocorrendo agrupamento com 48 horas e com 72 horas mantiveram-se espalhadas adentrando no biomaterial, apresentando morfologia arredondada na maioria das observações (Figura 2).
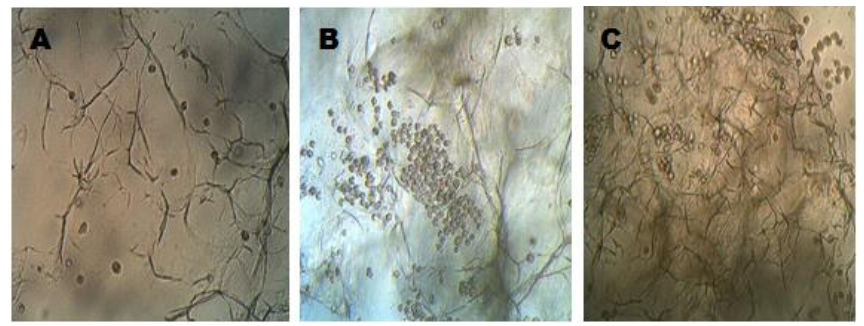

Figura 2. Fotomicrografias referente ao processamento histológico da esponja do biopolímero de cana-de-açúcar com a presença de células J774 observadas em microscópio invertido com contraste de fase. A) Nota-se aspecto irregular do biomaterial com a presença dos macrófagos com 24 horas; B) as células tendem a se agruparem com 48 horas e C) com 72 horas, percebem-se células infiltradas por todo o arcabouço. Todas as imagens com aumento de $100 \mathrm{X}$.

Os resultados obtidos com o processamento histológico, também revelaram células (J744) em associação com o arcabouço (3D), destacando-se a morfologia arredondada na maioria das observações (Figura 3).
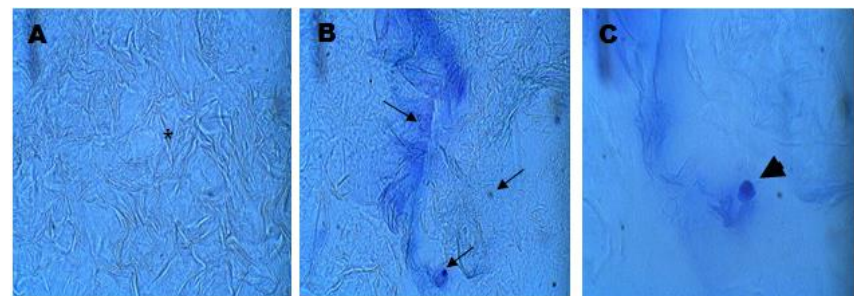

Figura 3. Arcabouço (3D) de biopolímero de cana-de-açúcar após processamento histológico, preparações histológicas coradas com azul de toluidina e imagens fotografadas em microscópio óptico. A) Aspecto da esponja após corte histológico, malha com dobras em direções variadas (asterisco). B) presença de células no arcabouço 3D (setas finas) e C) Nota-se macrófago arredondado na ponta da seta (aumento: 400X). A e $B$, aumento de $100 \mathrm{X}$
Como descrito por Junqueira e Carneiro (2013), os macrófagos têm características morfológicas bastante variáveis que dependem de seu estado de atividade funcional e do tecido que habitam. No entendimento histológico, os macrófagos derivam de células precursoras da medula óssea que se dividem, produzindo os monócitos. Em nossa avaliação histológica dos arcabouços 3D (esponjas de BCA) foi possível observar células com aspecto reniforme semelhantes a monócitos (Figura 4).

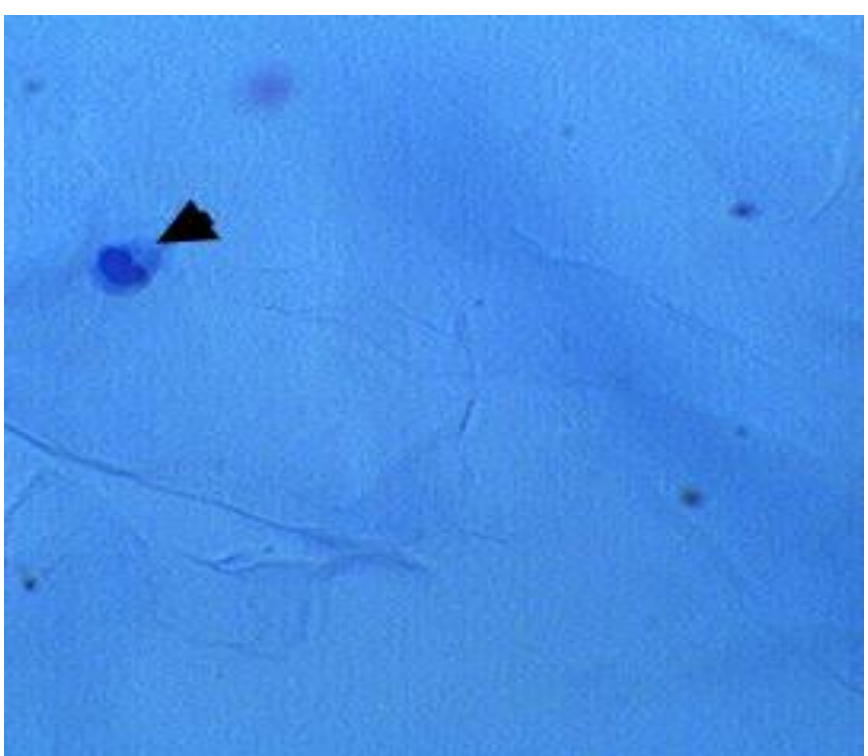

Figura 4. Imagem de macrófago com aspecto reniforme, semelhante a um monócito (cabeça de seta). Aumento: 400X.

Observamos com o auxílio da microscopia eletrônica de varredura que a estrutura da malha do biopolímero de cana-de-açúcar foi capaz de permitir a ancoragem dos macrófagos e mediar à comunicação com células adjacentes (Figura 5).
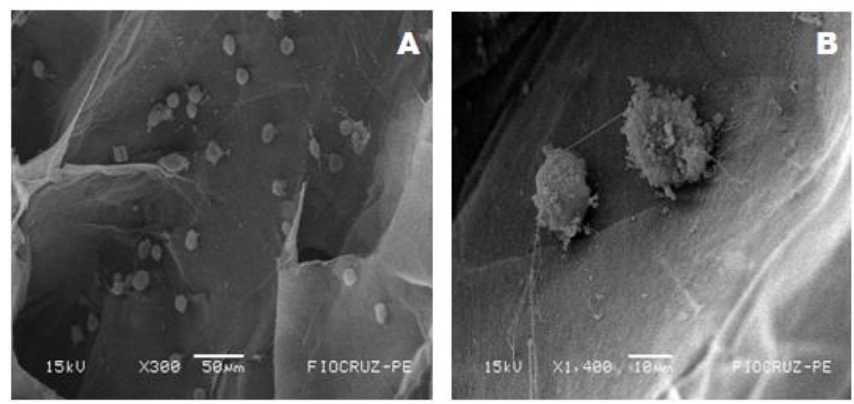

Figura 5. Microscopia eletrônica de varredura do processo de adesão de macrófagos $\mathrm{J774}$ com os arcabouços esponjosos a base de biopolímero de cana-de-açúcar. A) Observa-se 0 aspecto folheado do biosuporte e a presença de macrófagos ancorados ao mesmo. B) Nota-se células aderidas ao biomaterial por meio de finas projeções. Escalas de barra: 50 $\mu \mathrm{m}(\mathrm{A})$ e $10 \mu \mathrm{m}$ (B).

Araújo e colaboradores (2014) referem haver um grande interesse em pesquisas com polímeros naturais voltados para a regeneração da pele entre outros tecidos, o que reforça a busca por materiais com potencial viabilidade econômica como o biosuporte a base de cana-de-açúcar, oriundo de uma matéria-prima abundante da região do Nordeste brasileiro. Vale ressaltar que este é o primeiro relato do cultivo de macrófagos $\mathrm{J774}$ em arcabouços a base de biopolímero de cana-de-açúcar e estudos futuros poderão nortear as suas possíveis aplicações. Além do que, deve-se levar em conta, que modelos de cultura celular estão se tornando prevalentes na investigação das respostas dos tecidos aos diferentes tipos de implantes (BARBANTI; ZAVAGLIA, 2005; GRAJEIRO, 2007; PLACE; EVANS; STEVENS, 2009; MAGER et al., 2011) e uso de novos arcabouços in vitro pode reduzir a extensão de testes em animais (VICTAL et al., 2014; PIRES et al., 2015). 


\section{CONCLUSÕES}

Os arcabouços esponjosos a base de biopolímero de cana-de-açúcar mostraram-se biocompatíveis e capazes de proporcionar o desenvolvimento dos macrófagos J774. Dessa forma, faz-se necessário intensificar os estudos na área de polímeros voltados para a engenharia de tecidos, para que em um futuro próximo seja possível oferecer uma aplicabilidade real desses materiais e, assim, fornecer ferramentas capazes de auxiliar os métodos convencionais nos processos de regeneração tecidual.

\section{REFERÊNCIAS}

ABREU, T. C.; LIMA, R. P.; SOUZA, V. S. B.; CAMPOS-JÚNIOR, O.; ALBUQUERQUE, A. V.; AGUIAR, J. L. A.; ANDRADE, E. S. S.; VASCONCELOS, B. C. E. The polymer sugarcane as filling material of critical defects in rats. Acta Cirúrgica Brasileira; Rio de Janeiro, v. 31, n. 1, p. 53-58, 2016.

AGUIAR, J. L. A.; LINS, E. M.; MARQUES, S. R. B.; COELHO, A. R. B.; ROSSITER, R. O.; MELO, R. J. V. Sugarcane biopolymer patch in femoral artery angioplasty on dogs. Acta Cirúrgica Brasileira; Rio de Janeiro, v. 22, p. 77-81, 2007.

ARAÚJO, P. H. C.; DIAS, M. R. P.; AGUIAR, J. L. A.; SILVA, M. B.; SILVA, E. C.; MEDEIROS, P. L. 2014. Diferenciação de células-tronco mesenquimais de cordão umbilical humano em queratinócitos sobre biomembranas de cana-de-açúcar. Revista Enfermagem Atual In Derme, Rio de Janeiro, v. 68, n. 6, p. 18-21, 2014.

BARBANTI, S. E ZAVAGLIA, C. 2005. Polímeros Bioreabsorvíveis na Engenharia de Tecidos. Polímeros: Ciência e Tecnologia, São Carlos, v.15, p. 13-21, 2005.

BOROJEVIC, R. Terapias Celulares e Bioengenharia. Gazeta Médica da Bahia, Bahia, v. 78, n.1, p. 4246, 2008.

CARVAlHO, A. C. A.; PEREIRA, E. S. C.; COSTA, C.; BARRETO, I. C.; MADUREIRA, L. C.; PAIM, F. R. Estratégias regenerativas da bioengenharia tecidual e aspectos éticos. Revista das Ciências Médicas e Biológicas, Bahia, v. 9, p. 20-27, 2010.

CASTRO, C. M. M. B.; AGUIAR, J. L. A.; MELO, F. A. D.; SILVA, W. T. F.; MARQUES, E.; SILVA, D. B. 2004. Citotoxicidade de biopolímero de cana-de-açúcar. Anais da Faculdade de Medicina da Universidade Federal de Pernambuco, Pernambuco, v. 49, n.2, p. 119-123, 2004.

CAVAlCANTE, A. H. M., CARVAlHO, J. L. B., CARNEIRO-CUNHA, M. G. Journal of Biochemical Engineering, v. 29, p. 258-261, 2007.

GRANJEIRO, J. M. Papel dos biomateriais e da bioengenharia na medicina regenerativa. Innovations Implant Journal: Biomaterials and Esthetics, v. 1, n. 2, 16-27, 2007.

HOSSEIKHANI, M.; MERAHBANI, D.; KARIMFAR, M. H.; BAKHTIYARI, S.; MANAFI, A.; SHIRAZI, R. Tissue engineered scaffolds in regenerative medicine. World Journal of Plastic Surgery, v. 3, n. 1, p. 3-7, 2014.

JUNQUEIRA, L. C.; CARNEIRO, J. Histologia Básica - Texto e Atlas 2013. $12^{\mathrm{a}}$ Ed. Rio de Janeiro: Guanabara Koogan, pp. 538.

KIRKPATRICK, C. J. Biological testing of materials and medical devices - A critical view of current and proposed methodologies for biocompatibility testing: cytotoxicity in vitro. Regulatory Affairs, v. 4, n. 1, p. 13-32, 1992.

MADLA, S.; MIETHACONONE, P.; PRASITSILB, M.; KIRTIKARA, K. Characterization of fungi-derived polymers that are biocompatible and inducers IL-8 production. Carbohydrate Polymers, v. 59, p. 275-280, 2005.

MAGER, M. D.; LA POINTE. V.; STEVENS, M. M. Exploring and exploiting chemistry at the cell surface. Nature, v. 3, p. 582-589, 2011.

MARTINS, A. G. S.; CORREIA LIMA, S. V.; ARAÚJO, L. A. P.; VILAR, F. O.; CAVALCANTE, N. T. P. A wet dressing for hypospadias surgery. International Brazilian Journal of Urology, v. 39, n. 3, p. 408-413, 2013.

MAYER, D. L. B.; ARAÚJO, J. G.; LEAL, M. C.; CALDAS NETO, S. S.; ATAÍDE, R. F.; MELLO, R. J. V. 2011. Membrana do biopolímero da cana-de-açúcar: avaliação experimental na orelha média. Brazilian Journal of Otorhinolaryngology, v. 77, n. 1, p. 44-50, 2011.

PATTERSON-BEEDLE, M. KENNEDY, J. F.; MELO, F. A. D.; LLOYD, L. L.; MEDEIROS, V. A cellulosic exopolysaccharide produced from sugarcane molasses by a Zoogloea sp. Carbohydrate Polymers, v. 42, n.4, p. 375-383, 2000.

PÉRTILE, R. A. N., SIQUEIRA JR, J. M., RAMBO, C. R., BERTI, F. V., DO VALLE, R. M. R., PORTO, L. M. Interação de culturas celulares com suportes biopoliméricos para aplicações biomédicas. Exacta, São Paulo, v. 5, n. 2, p. 343-352, 2007.

PlaCE, E. S.; EVANS, N. D.; STEVENS, M. M. Complexity in biomaterials for tissue engineering. Nature Biomaterials, v. 8, p. 457-470, 2009.

SÀNDOR, G. K. Tissue engineering: Wave of change. Annals of Maxillofacial Surgery, v. 3, n. 1, p. 1-2, 2013.

SANTOS JR, A. R.; WADA, M. L. F. Polímeros biorreabsorvíveis como substrato para cultura de células e engenharia tecidual. Polímeros: Ciência e Tecnologia, v. 17, n. 4, p. 308-317, 2007.

SILVA, D. B.; AGUIAR, J. L. A.; MARQUES, A.; COELHO, A. R. B.; ROLIM FILHO, E. L. Miringoplastia com enxerto livre de membrana de biopolímero de cana-de-açúcar e fascia autóloga em Chinchilla laniger. Anais da Faculdade de Medicina da Universidade Federal de Pernambuco, v. 51, n. 1, p. 45-51, 2006.

SILVEIRA, A. A.; DANTAS, M. L. M.; ALMEIDA, Y. M. B.; AGUIAR, J. L. A. Estudo biomecânico de membranas de biopolímero de canade-açúcar perfuradas e contínuas implantadas no celular subcutâneo da parede abdominal de ratos. Anais da Faculdade de Medicina da Universidade Federal de Pernambuco. v. 52, n.1, p. 55-59, 2007.

SILVEIRA, A. B. F. N.; AGUIAR, J. L. A.; CAMPOS JÚNIOR, O.; DINIZ, G. T.; CORREIA LIMA, S. V. 2014. Biopolymer membrane of sugarcane: a reality as an option for the correction of urinary incontinence. Millenium, Portugal, v. 46, 81-95, 2014.

VICTAL, J. C.; VALÉRIO, L. B.; OSHIRO, M. C.; BAPTISTA, S. C.; PINHEIRO, F. Métodos alternativos in vitro e in silico: métodos auxiliares e substitutivos à experimentação animal. Revlnter Revista Intertox de Toxicologia, Risco Ambiental e Sociedade, v. 7, n. 2, p. 36-57, 2014.

WILSON, K. 1997. Wound Healing: the role of macrophages. Nurs Critical Care, v. 2, n. 6, p. 291-296, 1997.

\section{APOIO}

Propesq (UFPE) e CNPq 